Bài báo khoa học

\title{
Khảo sát diễn biến tình hình nhiễm Fluor răng (dental fluorosis) trên địa bàn thị xã Ninh Hòa, tỉnh Khánh hòa
}

\author{
Huỳnh Tiến Đạt ${ }^{1^{*}}$, Hoàng Thị Thanh Thủy ${ }^{1}$, Cấn Thu Văn ${ }^{1}$, Từ Thị Cẩm Loan ${ }^{1}$, Bùi \\ Thế Vinh ${ }^{1}$
}

${ }^{1}$ Trường Đại học Tài nguyên và Môi trường thành phố Hồ Chí Minh, 236B Lê Văn Sỹ, Phường 1, Quận Tân Bình, Thành phố Hồ Chí Minh; datht@hcmunre.edu.vn; httthuy@hcmunre.edu.vn; ttcloan@hcmunre.edu.vn; ctvan@hcmunre.edu.vn

*Tác giả liên hệ: datht@hcmunre.edu.vn; Tel: +84-977888777

Ban Biên tập nhận bài: 16/4/2021; Ngày phản biện xong: 21/5/2021; Ngày đăng bài: $25 / 6 / 2021$

Tóm tắt: Bệnh nhiễm fluor răng (Dental fluorosis) - một bệnh răng miệng cộng đồng thường gặp, nhưng có thể phòng ngừa được do nguyên nhân tăng cao quá mức flour trong các nguồn nước dưới đất. Hiện nay, nhiễm fluor răng vẫn là một vấn đề sức khỏe cộng đồng lớn trên toàn thế giới, trong đó có Việt Nam. Các nghiên cứu trước đây được thực hiện từ những năm 2000 đã chứng minh mối liên hệ giữa cải thiện sức khỏe răng miệng và nồng độ flo $(\mathrm{F})$ cao trong nước uống (nước giếng) ở thị xã Ninh Hòa, tỉnh Khánh Hòa. Do đó, một nghiên cứu về diễn biến nguy cơ nhiễm dental fluorosis trong cộng đồng đã được thực hiện. Kết quả khảo sát bằng bảng hỏi đã cho thấy tỷ lệ dân số có nguy cơ mắc bệnh dental fluorosis đã giảm so với các nghiên cứu trước đây. Đặc biệt, ngay tại khu vực dễ bị tổn thương là những khu vực có hàm lượng $\mathrm{F}$ cao $(>6 \mathrm{mg} / \mathrm{L})$ như thôn Ninh Xuân và Ninh Phụng, số dân số có nguy cơ nhiễm bệnh đã giảm xuống chỉ còn 18 và $12 \%$. Nhìn chung, chỉ có $25 \%$ dân số của thị xã Ninh Hòa có nguy cơ mắc bệnh dental fluorosis. Đó là kết quả từ việc thực hiện các dự án cấp nước sạch của chính phủ. Tuy nhiên, trong thời gian tới vẫn cần tăng cường hơn nữa các dự án này để có thể thay thế hoàn toàn việc sử dụng nước giếng trong cộng đồng. Bên cạnh đó, cũng cần triển khai các nghiên cứu chi tiết hơn về tình hình dịch tễ் và nguồn cung cấp $\mathrm{F}$ ở khu vực nghiên cứu.

Từ khóa: Thủy địa hóa; Ô nhiễm Fluor; Nước dưới đất; Nhiễm fluor răng.

\section{Mở đầu}

Flour $(\mathrm{F})$ là nguyên tố rất cần thiết cho cơ thể sống. Tuy nhiên, khi nồng độ $\mathrm{F}$ trong nước uống cao hơn mức 1,5 ppm sẽ gây tác hại lâu dài cho sức khỏe, đặc biệt gây bệnh nhiễm flo răng (dental fluorosis) [1-3]. Theo y văn, bệnh dental fluorosis được định nghĩa là răng bị nhiễm độc mãn tính bởi $\mathrm{F}$ do sử dụng nước uống có nồng độ $\mathrm{F}$ cao [1]. Người nhiễm bệnh xuất hiện những đóm nâu, đen trên răng và có thể hình thành các mảng, lỗ gây hại cho men răng. Ô nhiễm $\mathrm{F}$ trong nước uống là nguyên nhân chính trong tất cả các nguyên nhân gây bệnh dental fluorosis. Các kết quả nghiên cứu trước đây đã cho thấy 25 quốc gia trên thế giới có nồng độ florua cao trong các nguồn nước và khoảng 200 triệu người sống dựa vào các nguồn nước có chứa quá nhiều florua gây hậu quả nghiêm trọng đến sức khỏe người tiêu dùng [4-5]. Các quốc gia được ghi nhận trong bản đồ ô nhiễm fluor thế giới điển hình bao gồm Ethiopi (8 đến 10 triệu người bị ảnh hưởng; [6]); Mexico (5 triệu người bị ảnh hưởng; 
[7]); Argentina (1,2 triệu người; [8]). Châu Âu là khu vực có rủi ro thấp, chỉ có một số khu vực như Tây Ban Nha [9] và Nauy [10].

Ở Châu Á, các quốc gia có hàm lượng $\mathrm{F}$ cao bao gồm Ấn độ, Trung Quốc, Sri Lanka [2$3,11-12]$. Khoảng 66 triệu người dân Ân độ và 45 triệu người dân Trung Quốc sinh sống trong vùng có nguy cơ ô nhiễm. Ở Việt Nam, Bình Định, Khánh Hòa và Phú Yên là các địa phương có xuất hiện bệnh dental fluorosis [13-15]. Thị xã Ninh Hòa (tỉnh Khánh Hòa) là một trong những địa phương đầu tiên đã phát hiện dấu hiệu của bệnh. Các kết quả nghiên cứu giai đoạn 1990-2992 đã bước đầu kết luận nguyên nhân gây ra bệnh chết răng là do sự xuất hiện của dị thường $\mathrm{F}$ trong nước uống từ các giếng đào của người dân. Kể từ khi dấu hiệu bệnh hỏng men răng, người dân địa phương gọi là chết răng được đề cập đến từ năm 1985. Vào năm 1999, số người mắc bệnh dental fluorosis ở Ninh Hòa đã phát hiện được trên $76 \%$ dân số khảo sát có dấu hiệu mắc bệnh. Đến năm 2000, một nghiên cứu khá chi tiết về sự phân bố $\mathrm{F}$ trong các hợp phần môi trường tự nhiên (nước mặt, nước dưới đất và môi trường đất). Kết quả nghiên cứu cũng xác nhận người dân địa phương bị hỏng răng ở các mức độ khác nhau vì sử dụng nước giếng đào có hàm lượng fluor cao [15-17]. Gần đây nhất, kết quả phân tích cũng cho thấy sự hiện diện của dị thường $\mathrm{F}$ trong nước dưới đất ở khu vực Ninh Hòa. 50\% tổng số mẫu (trong tổng số 26 mẫu phân tích) đã có hàm lượng $\mathrm{F}$ cao hơn quy chuẩn cho phép [18]. Giá trị F lớn nhất đo được tại Xã Ninh Xuân đã lên tới $10 \mathrm{mg} / \mathrm{L}$, cao hơn giá trị giới hạn 7 lần.

Với thực tế hiện nay tuy nguồn nước cấp đã đến được nhiều nơi nhưng nước giếng vẫn được các hộ sử dụng rộng rãi, nhất là các hộ người dân tộc, thì nguy cơ tiếp diễn bệnh fluorosis vẫn là vấn đề cần được quan tâm của thị xã Ninh Hòa. Do đó, mục tiêu của đề tài là khảo sát sự chuyển biến đối với các bệnh về răng có thể liên quan đến dư lượng $\mathrm{F}$ trong cộng đồng ở khu vực thị xã Ninh Hòa. Phạm vi nghiên cứu là 11 xã thuộc thị xã Ninh hòa, là các địa phương đã được ghi nhận xuất hiện bệnh dental fluorosis trong các nghiên cứu trước đây.

\section{Phương pháp nghiên cứu}

Nhóm nghiên cứu đã tiến hành thu thập thông tin bằng phiếu khảo sát các hộ gia đình sinh sống tại 11 xã thuộc thị xã Ninh Hòa, tỉnh Khánh Hòa. Thông tin về các hộ khảo sát ở mỗi xã được tổng hợp tại Bảng 1.

Bảng 1. Thông tin về các hộ khảo sát thuộc địa bàn thị xã Ninh Hòa.

\begin{tabular}{|c|c|c|c|c|c|}
\hline \multirow{2}{*}{ STT } & \multirow{2}{*}{ X̃̃ } & \multirow{2}{*}{$\begin{array}{c}\text { Số hộ } \\
\text { khảo } \\
\text { sát }\end{array}$} & \multirow{2}{*}{$\begin{array}{c}\text { Thời gian sinh } \\
\text { sống tại địa } \\
\text { phương (năm) }\end{array}$} & \multicolumn{2}{|c|}{ Nguồn nước sử dụng } \\
\hline & & & & Nước thủy cục & Nước giếng \\
\hline & Ninh Bình (NB) & 4 & $27-65$ & $\mathrm{x}$ & $\mathrm{x}$ \\
\hline & Ninh Giang (NG) & 1 & 30 & & $\mathrm{x}$ \\
\hline & Ninh Hưng (NH) & 8 & $26-61$ & $\mathrm{x}$ & $\mathrm{x}$ \\
\hline & Ninh Phụng (NP) & 8 & $5-61$ & $\mathrm{x}$ & $\mathrm{x}$ \\
\hline & Ninh Quang (NQ) & 4 & $39-56$ & $\mathrm{x}$ & $\mathrm{x}$ \\
\hline & Ninh Sim (NS) & 13 & $28-60$ & & $\mathrm{x}$ \\
\hline & Ninh Tây (NT) & 6 & $2-64$ & $\mathrm{x}$ & $\mathrm{x}$ \\
\hline & Ninh Thân (NTha) & 10 & $10-57$ & $x(03)$ & $\mathrm{x}$ \\
\hline & Ninh Thượng (NThu) & 6 & $24-50$ & $\mathrm{x}$ & $\mathrm{x}$ \\
\hline & Ninh Trung (NTr) & 11 & $32-55$ & $x(02)$ & $\mathrm{x}$ \\
\hline & Ninh Xuân (NX) & 22 & $14-69$ & $\mathrm{x}(11)$ & $\mathrm{x}$ \\
\hline
\end{tabular}

Số lượng phiếu khảo sát là 93 phiếu bao gồm các thông tin về thời gian sinh sống tại địa phương, nguồn nước sử dụng, thông tin về giếng và dấu hiệu các bệnh răng có thể liên quan trong hộ gia đình. Do có hai phiếu khảo tại xã Ninh Tây có thời gian sinh sống tại địa phương 
ngắn $(<5$ năm) do đó đã loại ra khỏi dữ liệu để xử lý. Các thông tin ghi nhận được tổng hợp và đối sánh với các nghiên cứu trước đây ở khu vực nghiên cứu.

\section{Kết quả và thảo luận}

\subsection{Tình hình nhiễm độc flo trên răng}

Kết quả khảo sát của nhóm nghiên cứu vào năm 2019 đã cho thấy trong số 11 xã khảo sát đã có 8 xã có dấu hiệu vẫn còn người dân bị nhiễm bệnh dental fluorosis. Tỷ lệ người dân có các dấu hiệu nhiễm bệnh dental fluorosis được sắp xếp theo thứ tự giảm dần như sau:

Ninh Sim $(53 \%)>$ Ninh Trung $(45 \%)>$ Ninh Thượng $(33 \%)>$ Ninh Quang $(25 \%)>$ Ninh Xuân (18\%) > Ninh Tây (16\%) > Ninh Phụng (13\%) > Ninh Thân (10\%)

Khi so sánh với các nghiên cứu trước đây cho thấy tỷ lệ người dân nhiễm bệnh đã có xu thế giảm rõ rệt. Ví dụ trong các nghiên cứu trước đây thì Ninh Xuân, Ninh Phụng và Ninh Hương là các địa phương có tỷ lệ người mắc bệnh cao lên đến đều ở mức cao (67-97\%) [15]; và $100 \%$ [17]. Nhưng theo khảo sát của nhóm nghiên cứu, tỷ lệ người có dấu hiệu nhiê̂m bệnh cao nhất là ở xã Ninh Sim (53\%). Ở hai xã Ninh Bình và Ninh Hưng thì $100 \%$ người dân được khảo sát không có dấu hiệu nhiễm bệnh (Hình 1). Về mối tương quan giữa tỷ lệ người dân có dấu hiệu bị nhiễm bệnh với hàm lượng $\mathrm{F}$ trog nước giếng cũng có những khác biệt so với các kết quả đã công bố. Trước đây, Ninh Thượng và Ninh Xuân là hai xã có tỷ lệ người nhiễm bệnh cao nhất [15]. Tuy nhiên, đến thời điểm hiện nay thì Ninh Sim và Ninh Trung là hai xã có tỷ lệ người nhiễm bệnh cao hơn các địa phương khác. Các khu vực có lượng $\mathrm{F}$ ở mức cao $(>2 \mathrm{mg} / \mathrm{L})$ bao gồm các xã Ninh Phụng, Ninh Xuân, Ninh Bình và Ninh Tây đều có số lượng người có dấu hiệu dental fluorosis rất thấp. Còn ở các xã có tỷ lệ người dân có nguy cơ nhiễm bệnh cao như Ninh Sim lại là khu vực có hàm lượng $\mathrm{F}$ khá thấp $(0,96$ $\mathrm{mg} / \mathrm{l})$ [15]. Riêng đối với xã Ninh Trung là khu vực có hàm lượng $\mathrm{F}$ cao $(0,3-1,9 \mathrm{mg} / \mathrm{l})$ [7]; $(0,5-2,8 \mathrm{mg} / \mathrm{l})$ [8] thì tỷ lệ người dân có nguy cơ nhiễm bệnh tuy đã giảm nhưng vẫn còn ở mức cao $(45 \%)$.

Một minh chứng khác liên quan đến bệnh nhiễm $\mathrm{F}$ răng là thói quen sử dụng nước trong sinh hoạt. Xã Ninh Sim là khu vực có địa hình đồi núi thấp nằm về phía tây cách thị xã Ninh Hòa $13 \mathrm{~km}$. Theo khảo sát đã cho thấy người dân vẫn sử dụng nguồn nước giếng là chủ yếu. Thời gian sử dụng giếng thay đổi từ 25 đến 40 năm, ngoại lệ là 50 năm.
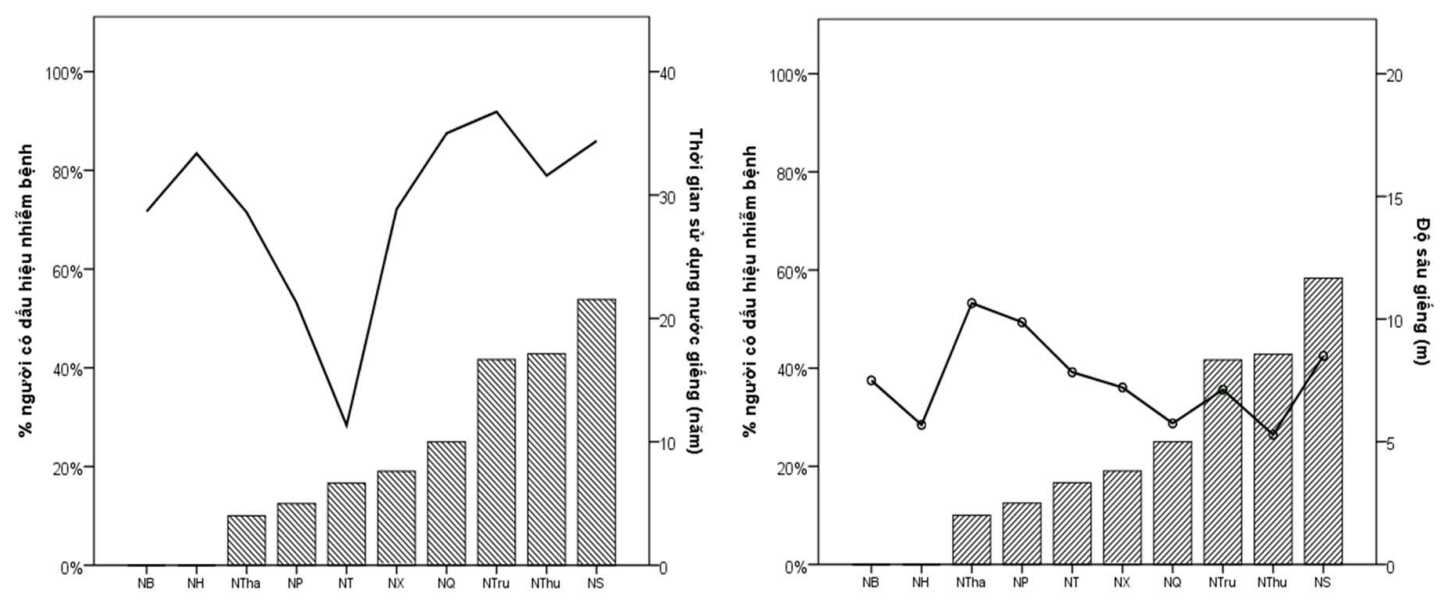

Hình 1. Tỷ lệ người có dấu hiện nhiễm bệnh liên quan đến thời gian sử dụng nước giếng và độ sâu giếng.

Thôn Đống Đa là khu vực có nhiều người có dấu hiệu nhiễm bệnh với thời gian sinh sống ở địa phương từ 28-60 năm. Tương tự, ở xã Ninh Trung, nguồn nước sử dụng chủ yếu là nước giếng từ 30-50 năm. Người dân có dấu hiệu nhiễm dental fluorosis như vàng răng, 
đục răng đều là người dân sinh sống trên 30 năm tại thôn Quảng Cư. Ở các xã khác có sử dụng cả hai nguồn nước thì tỷ lệ người dân có dấu hiệu nhiễm dental fluorosis đều giảm.

\subsection{Nguồn cung cấp F trong nước dưới đất}

Sự hình thành hàm lượng $\mathrm{F}$ cao trong nước dưới đất có thể có nhiều nguyên nhân từ hoạt động của con người (nước thải công nghiệp, phân hoá học trong nông nghiệp, chất thải công nghiệp hoặc từ các nghĩa trang) và đặc điểm địa chất khu vực (thành phần đất đá, từ các mỏ fluor và nước khoáng-nước nóng giàu $\mathrm{F}$ ). Tại thời điểm năm 2000, hàm lượng $\mathrm{F}$ trong nước dưới đất (nước giếng) đã được thực hiện khảo sát tại 13 xã trên địa bàn khu vực Ninh Hòa (Ninh Tây, Ninh Sim, Ninh Xuân, Ninh Thân, Ninh Thượng, Ninh Phụng, Ninh Trung, Ninh Hòa, Ninh Quang, Ninh Hưng, Ninh Thọ và Ninh An) có khoảng biến thiên từ 0,1 đến 6,8 $\mathrm{mg} / \mathrm{l}$. Dị thường của $\mathrm{F}$ là $1 \mathrm{mg} / \mathrm{L}$ và $1,5 \mathrm{mg} / \mathrm{L}$ đã phát hiện trong $41 \%$ và $37 \%$ tổng số mẫu phân tích. Gần đây nhất, vào năm 2017, kết quả khảo sát được thực hiện trên địa bàn 6 xã (Ninh Xuân, Ninh Thân, Ninh Quang, Ninh Thượng, Ninh Phụng và Ninh Trung đã cho thấy hàm lượng $\mathrm{F}$ trong nước dưới đất vẫn ở mức cao. Hai dị thường $\mathrm{F}$ là $1 \mathrm{mg} / \mathrm{L}$ và $1,5 \mathrm{mg} / \mathrm{L}$ đã phát hiện trong $27 \%$ và $47 \%$ tổng số mẫu phân tích. Tại khu vực xã Ninh Xuân đã xác định được nồng độ $\mathrm{F}$ lên đến $11 \mathrm{mg} / \mathrm{L}$ [18]. Do đó có thể nói nguồn nước giếng tại khu vực thị xã Ninh Hòa vẫn liên tục được bổ sung $\mathrm{F}$.

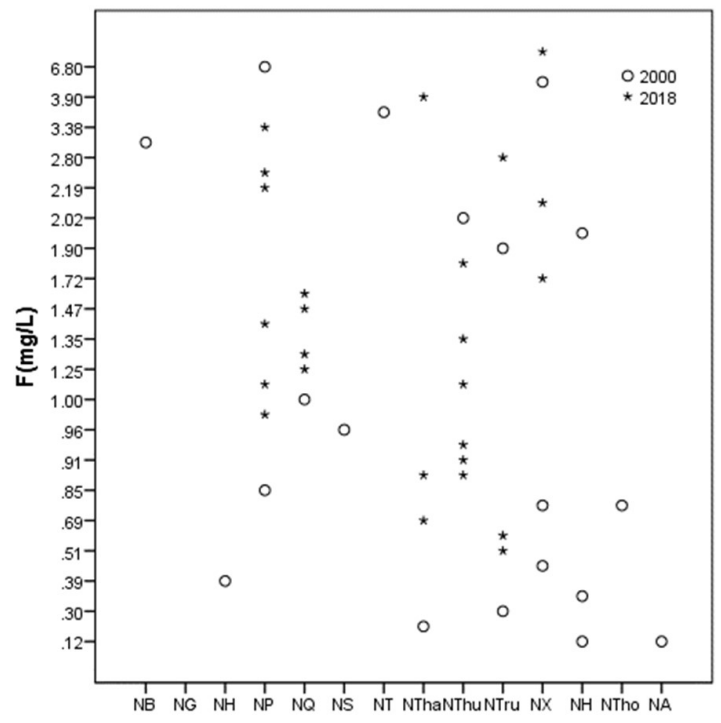

Hình 2. Diễn biến hàm lượng $\mathrm{F}$ trong nước dưới đất khu vực thị xã Ninh Hòa, tỉnh Khánh Hòa [14-

18].

Các nghiên cứu trước đây đã chỉ ra rằng nguyên nhân hình thành nồng độ $\mathrm{F}$ cao trong nước ngầm ở Ninh Hòa là do đặc điểm địa chất khu vực. Các dị thường $\mathrm{F}$ trong nước dưới đất hiện diện ở các khu vực có hoạt động công nghiệp, sử dụng phân hoá học trong nông nghiệp, chất thải công nghiệp hoặc chất bẩn từ các nghĩa trang không nhiều, nên nguyên nhân nhân tạo không có khả năng gây ra sự ô nhiễm fluor cho nước dưới đất. Sự phân bố không gian của $\mathrm{F}$ trong nước dưới đất ở Ninh Hòa không đồng đều thể hiện qua sự đan xen giữa các vùng hàm lượng $\mathrm{F}$ cao và thấp, hình thành hai tuyến tương đối rõ: một tuyến kéo dài theo phương $\mathrm{T}-\mathrm{Ð}$ từ Ninh Tây đến Ninh Quang và tuyến khác theo phương $\mathrm{TN}-\mathrm{DB}$ từ Ninh Xuân đến Ninh Thượng. Do đó, $\mathrm{F}$ được xác định là có nguồn gốc từ các thành tạo địa chất dưới sâu và di chuyển thông qua hệ thống kênh dẫn có áp là các đứt gãy kiến tạo, các đới phá hủy và khe nứt. Vùng Ninh Hòa nằm ở rìa $\mathrm{DN}$ địa khối Kon Tum, trong đới hoạt hóa $\mathrm{MZ}-\mathrm{KZ}$, đặc trưng bằng các hoạt động magma xâm nhập và phun trào-trầm tích đa dạng, thuộc các hệ 
tầng Mang Yang, Nha Trang, La Ngà, đèo Bảo Lộc. Đá magma tiêu biểu là các đá granitoid thuộc các phức hệ Định Quán, Đèo Cả và Cà Ná. Trong các đá này có mặt nhiều khoáng vật có chứa $\mathrm{F}$ như biotit, muscovit, apatit và đặc biệt là fluorit, v.v... Thêm vào đó, trong vùng có điểm quặng Hòn Sạn, nguồn gốc nhiệt dịch, nằm trong khối xâm nhập granit và fluorit là một thành phần đi kèm với khoáng vật molybdenit và các khoáng vật chứa Ta.

Bảng 2. Hàm lượng F (\%) trong các khoáng vật liên quan đến các đá magma granit [12].

\begin{tabular}{ccc}
\hline Khoáng vật & Thành phần hóa học & Hàm lượng F (\%) (*) \\
\hline Fluorit & $\mathrm{CaF}_{2}$ & $47,81-48,80$ \\
Biotit & $\mathrm{K}(\mathrm{Mg}, \mathrm{Fe})_{3}\left[\mathrm{AlSi}_{3} \mathrm{O}_{10}(\mathrm{OH}, \mathrm{F})\right]_{2}$ & $0,08-3,5$ \\
Muscovit & $\mathrm{KAl}_{2}\left(\mathrm{AlSi}_{3} \mathrm{O}_{10}\right)(\mathrm{F}, \mathrm{OH})$ & $0,02-2,95$ \\
Apatit & $\mathrm{Ca}_{5}\left(\mathrm{PO}_{4}\right)_{5}(\mathrm{~F}, \mathrm{Cl}, \mathrm{OH})$ & $1,35-3,77$ \\
\hline
\end{tabular}

Sự xuất hiện của các nguồn nước khoáng nóng cũng có thể là nguồn cung cấp $\mathrm{F}$ trực tiếp khối lượng lớn nhất. Từ các khe nứt trong đá xâm nhập granitoid hoặc phun trào axit, $\mathrm{F}$ có thể xuất lộ trên mặt đất theo các nguồn nước khoáng nóng với lưu lượng lớn, chảy liên tục. Hàm lượng $\mathrm{F}$ trong nước khoáng rất cao, lên đến 9-9,3 mg/l (Buôn M’Dung). Vì vậy các giếng nước ở gần điểm xuất lộ nước khoáng, đều có hàm lượng fluor khá cao ví dụ như ở xã Ninh Tây. Mặt khác, kết quả khảo sát cũng cho thấy các giếng ở những hộ có nguy cơ nhiễm dental fluorosis thường là các giếng cố độ sâu $<10 \mathrm{~m}$. Do đó rất có thể đã có đã những nguồn cung cấp $\mathrm{F}$ khác cho tầng chứa nước.

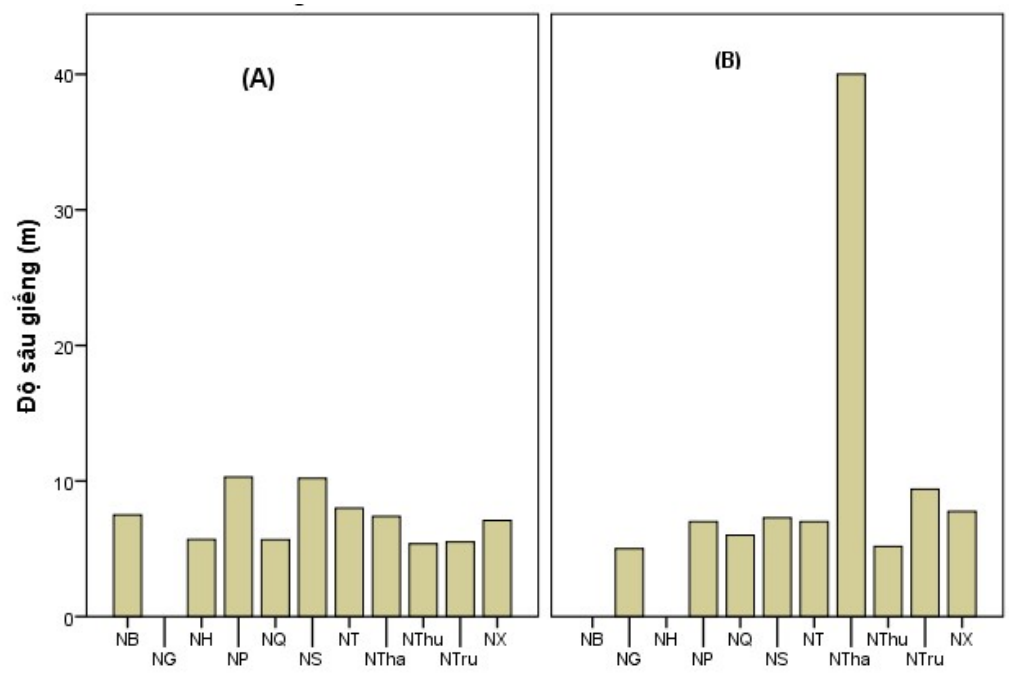

Hình 3. Mối tương quan giữa độ sâu giếng và nguy cơ nhiễm bệnh dental fluorosis.

(A: Khu vực không có người nhiễm bệnh, $\mathrm{B}$ : khu vực có người nhiễm bệnh)

Tóm lại, tuy tỷ lệ người dân có nguy cơ nhiễm dental flurorosis đã giảm đáng kể so với các kết quả đã công bố nhưng vẫn cần có nghiên cứu chi tiết hơn để đánh giá lại nguồn gốc của $\mathrm{F}$ trong nước dưới đất và hệ quả đến sức khỏe cộng đồng ở khu vực nghiên cứu.

\section{Kết luận}

Sự hiện diện của nồng độ cao ion $\mathrm{F}$ trong nước ngầm là một vấn đề lớn, nó làm cho nước không phù hợp để sử dụng cho mục đích ăn uống. Việc sử dụng nước có nồng độ florua cao lâu dài sẽ gây ảnh hưởng tiềm tàng đến sức khỏe con người. Hiện tượng nhiễm bệnh dental fluorosis ở khu vực thị xã Ninh Hòa, tỉnh Khánh Hòa có tính chất lịch sử. Hiện nay, do nhiều khu vực đã được cung cấp nước máy nên tình hình nhiễm bệnh đã có dấu hiệu chuyển biến tích cực. Tỷ lệ người dân có dấu hiệu nhiễm bệnh đã giảm rất nhiều so với các kết quả nghiên cứu trước đây. Tuy nhiên, kết quả điều tra cho thấy người dân vẫn có thói quen sử dụng nước giếng trong sinh hoạt. Nguồn cung cấp $F$ chủ yếu là thành phần khoáng vật của các đá magma 
xâm nhập và phun trào axit cùng với các nguồn nước khoáng, nước nóng. Các đới phá hủy kiến tạo đóng vai trò như những hệ thống kênh dẫn $\mathrm{F}$ có áp đến các giếng nước của hộ dân. Do đó, nếu người dân vẫn tiếp tục sử dụng nước giếng thì nguy cơ nhiễm bệnh dental fluorosis sẽ vẫn tiếp tục xảy ra. Chính vì vậy, cần nâng cao nhận thức cộng đồng để người dân từ bỏ thói quen sử dụng nước giếng để không làm ảnh hưởng đến sức khỏe cộng đồng. Bên cạnh đó, cũng cần triển khai các nghiên cứu chi tiết hơn để làm sáng tỏ các nguồn gốc khác của $\mathrm{F}$ ở khu vực nghiên cứu. Để bảo vệ sức khỏe cộng đồng, các điều tra dịch tễ học liên quan đến bệnh dental fluorosis cũng vẫn cần được triển khai rộng rãi, đặc biệt là trong chương trình khám sức khỏe ở các trường học.

Đóng góp cho nghiên cứu: Xây dựng ý tưởng nghiên cứu: H.T.Đ., H.T.T.T.; Lựa chọn phương pháp nghiên cứu: H.T.Đ.; Thu thập, phân tích, xử lý số liệu: H.T.Đ., T.C.L.; Viết bản thảo bài báo: H.T.Đ., C.T.V.; Chỉnh sửa bài báo: B.T.V.

Lời cảm ơn: Nghiên cứu này được thực hiện dưới sự tài trợ của đề tài nghiên cứu khoa học cấp tỉnh, mã số ĐT.08-2018.

Lời cam đoan: Tập thể tác giả cam đoan bài báo này là công trình nghiên cứu của tập thể tác giả, chưa được công bố ở đâu, không được sao chép từ những nghiên cứu trước đây; không có sự tranh chấp lợi ích trong nhóm tác giả.

\section{Tài liệu tham khảo}

1. Kimambo, V.; Bhattacharya, P.; Mtalo, F.; Mtamba. J.O.D. Fluoride occurrence in groundwater systems at global scale and status of defluoridation - State of the art.

Groundwater Sustainable Dev. 2019, 9, 100-223. https://doi.org/10.1016/j.gsd.2019.100223.

2. Yadav, K.K.; Kumar, S.; Pham, Q.B.; Gupta, N.; Rezania, S.; Kamyab, H.; Yadav, S.; Vymazal, J.; Kumar, V.; Tri, D.Q.; Talaiekhozani, A.; Prasad, S.; Reece, L. M.; Singh, N.; Maurya, P.K.; Gho, j. Fluoride contamination, health problems and remediation methods in Asian groundwater: A comprehensive review. Ecotoxicol. Environ. Saf. 2019, 182, 109362.

3. Mukherjee, I.; Singh, U.K. Groundwater fluoride contamination, probable release, and containment mechanisms: a review on Indian context. Environ. Geochem. Health. 2018, 40(6), 2259-2301.

4. Vithanage, M.; Prosun, B. Fluoride in drinking water: health effects and remediation. In: Environmental Chemistry for a Sustainable World. 2015a, 105-151.

5. Vithanage, M.; Prosun, B. Fluoride in the environment: sources, distribution and defluoridation. Environ. Chem. Lett. 2015b, 13(2), 131-147.

6. Rango, T.; Kravchenko, J.; Atlaw, B.; McCornick, P.G.; Jeuland, M.; Merola, B.; Vengosh, A. Groundwater quality and its health impact: an assessment of dental fluorosis in rural inhabitants of the main Ethiopian rift. Environ. Int. 2012, 43(1), 3747. https://doi.org/10.1016/j.envint.2012.03.002.

7. Farooqi, A. Arsenic and fluoride pollution in water and soils. Arsenic Fluoride Contam. 2015, 1-16.

8. Borgnino, L.; Garcia, M.G.; Bia, G.; Stupar, Y.V.; Le Coustumer, Ph.; Depetris, P.J. Mechanisms of fluoride release in sediments of Argentina's central region. Sci. Total Environ. 2013, 443, 245-255.

9. Hardisson, A.; Rodríguez, M.; Burgos, A.; Díaz Flores, L.; Gutiérrez, R.; Várela, H. Fluoride Levels in Publicly Supplied and Bottled Drinking Water in the Island of Tenerife, Spain. Bull. Environ. Contam. Toxicol. 2001, 67, 163-170. https://doi.org/10.1007/s001280106.

10. Bårdsen, A.; Klock, K.S.; Bjorvatn, K. Dental fluorosis among persons exposed to high- and low-fluoride drinking water in western Norway. Community Dent. Oral Epidemiol. 1999, 27(4), 259-267. 
11. Edmunds, W.M.; Smedley, P.L. Fluoride in Natural Waters: Essential of Medical Geology. British Geological Survey Commissioned Report 2013, 311-336.

12. Dissanayake, C.B.; Chandrajith, R. Introduction to Medical Geology. Erlangen Earth Conference Series, Springer-Verlag Berlin Heidelberg. 2010. ISBN 978-3642-00484-1.

13. Nguyệt, P.N.; Hiền, T.T. Ô nhiễm fluoride trong nước ngầm và đánh giá phơi nhiễm fluoride cho người dân huyện Tây Sơn, tỉnh Bình Định. Tạp chí phát triển khoa học và công nghệ 2013, 16, 61-72.

14. Hoan, Đ.K.; Trân, V.N.; Bảo, N.D.; Tiến, N.Đ. Sự phân bố nước dưới đất bị nhiễm fluor ở tỉnh Khánh Hòa và các giải pháp xử lý. Tạp chí địa chất 2008, 296, 112-118.

15. Thuận, Đ.T.; Tú, Đ.T. Ô nhiễm fluor và bệnh chết răng ở vùng Nam Trung bộ. Tạp chi dịa chất 2008, 309. http://phantichmoitruong.com/detail/o-nhiem-fluor-va-benhchet-rang-o-vung-nam-trung-bo-.html.

16. Tín, Q.Đ.; Huyền, Đ.T.N. Địa hóa nguyên tố fluor và vai trò đối với sức khỏe cộng đồng ở Việt Nam. Viện Khoa học Địa chất và Khoáng sản, 2008.

17. Sĩ, H.T.; Liêm, N.T. Nghiên cứu tình hình nhiễm độc flo trên răng vĩnh viễn của người dân huyện Ninh Hòa - Khánh Hòa và xây dựng qui trình xử lý flo trong nước giếng. Tạp chi Y hoc thưc hành 2010, 699+700.

18. Huyền, Đ.T.; Quang, N.N.; Bách, N.D.; Thịnh, Trông, N.T.H.; Anh, N.N. Ô nhiễm Fluoride trong nước dưới đất tại huyện Ninh Hòa, tỉnh Khánh Hòa. Hội nghị Khoa học Công nghệ 15, 2017.

\title{
Temporal variation of dental fluorosis in Ninh Hoa district, Khanh Hoa Province
}

\author{
Huynh Tien Dat ${ }^{1 *}$, Hoang Thi Thanh Thuy ${ }^{1}$, Can Thu Van ${ }^{1}$, Tu Thi Cam Loan${ }^{1}$, Bui \\ The Vinh ${ }^{1}$ \\ ${ }^{1}$ Hochiminh City Univeristy of Natural Resources and Environment, 236B Le Van Sy, 1 \\ Ward, Tan Binh district, Hochiminh City; datht@hcmunre.edu.vn; \\ httthuy@hcmunre.edu.vn; ttcloan@hcmunre.edu.vn; ctvan@hcmunre.edu.vn
}

\begin{abstract}
Dental fluorosis-a major, but preventable, oral diseases and public oral health problems-related with exceeded the fluoride level in natural groundwater sources. Dental fluorosis remains as a major public health problem worldwide, including Vietnam. Previous studies carried out since the 2000s demonstrated a link between dental fluorosis and increased fluoride levels in drinking water of Ninh Hoa town, Khanh Hoa province. The aim of this study was to determine the temporal variation of district's population, who at risk for dental caries or dental fluorosis, with questionair survey in Ninh Hoa town. The results indicated that the rate of population at risk for dental fluorosis, has been decreased in comparision with previous studies. In especially, in the vulnerable area with high fluorid zones like Ninh Xuan, Ninh Phung wards $(>6 \mathrm{mg} / \mathrm{L})$, the number of population at risk decreases to only 18 and $12 \%$, respectively. Overall, only $25 \%$ district's population were risk of potential dental fluorosis. It is the results from implementation of drinking water supply projects from government. However, the long-term operation of the replacement of groundwater project need to be further strengthened. In addition, a further study on dental fluorosis and sources of $F$ should be carried out.
\end{abstract}

Keywords: Hydrogeochemistry; Contamination; Fluor; Groundwater; Dental fluorosis. 